Article

\title{
Improved Reliability and Mechanical Performance of Ag Microalloyed Sn58Bi Solder Alloys
}

\author{
Guang Ren *(D) and Maurice N. Collins * \\ Stokes Laboratories, Bernal Institute, University of Limerick, V94 T9PX Limerick, Ireland \\ * Correspondence: guang.ren@ul.ie (G.R.); maurice.collins@ul.ie (M.N.C.); \\ Tel.: +353-61-202449 (G.R.); +353-61-202449 (M.N.C.)
}

Received: 9 April 2019; Accepted: 18 April 2019; Published: 20 April 2019

\begin{abstract}
Ag microalloyed Sn58Bi has been investigated in this study as a Pb-free solder candidate to be used in modern electronics industry in order to cope with the increasing demands for low temperature soldering. Microstructural and mechanical properties of the eutectic Sn58Bi and microalloyed Sn57.6Bi0.4Ag solder alloys were compared. With the addition of Ag microalloy, the tensile strength was improved, and this was attributed to a combination of microstructure refinement and an $\mathrm{Ag}_{3} \mathrm{Sn}$ precipitation hardening mechanism. However, ductility was slightly deteriorated due to the brittle nature of the $\mathrm{Ag}_{3} \mathrm{Sn}$ intermetallic compounds (IMCs). Additionally, a board level reliability study of Ag microalloyed Sn58Bi solder joints produced utilizing a surface-mount technology (SMT) process, were assessed under accelerated temperature cycling (ATC) conditions. Results revealed that microalloyed Sn57.6Bi0.4Ag had a higher characteristic lifetime with a narrower failure distribution. This enhanced reliability corresponds with improved bulk mechanical properties. It is postulated that $\mathrm{Ag}_{3} \mathrm{Sn}$ IMCs are located at the $\mathrm{Sn}-\mathrm{Bi}$ phase boundaries and suppress the solder microstructure from coarsening during the temperature cycling, hereby extending the time to failure.
\end{abstract}

Keywords: Sn58Bi; Ag; microalloy; mechanical; reliability

\section{Introduction}

The implementation of legislation entitled "Restriction on the use of certain Hazardous Substances (RoHS)" in the European Union in July 2006 marked the beginning of the phasing out of conventional $\mathrm{Sn} 37 \mathrm{~Pb}$ (expressing $37 \mathrm{wt} . \% \mathrm{~Pb}$ and the balance is Sn concentration, similarly hereafter) eutectic solder in the electronic industry. RoHS has been since adopted in countries and regions with dense electronics manufacturing: Korea, Japan, China, and a range of US states [1]. In response, most major electronics manufacturers have stepped up their search for alternatives to $\mathrm{Pb}$-containing $(\mathrm{Sn} 37 \mathrm{~Pb}$ ) solders (i.e., $\mathrm{Pb}$-free solders). $\mathrm{Sn}-\mathrm{Ag}$, $\mathrm{Sn}-\mathrm{Cu}$, and $\mathrm{Sn}-\mathrm{Ag}-\mathrm{Cu}(\mathrm{SAC}) \mathrm{Pb}$-free eutectic or near eutectic systems have emerged as the front runners in the replacement of $S n 37 \mathrm{~Pb}$ solder [2]. Among them, near-eutectic SAC alloys have established themselves as the interconnect materials of choice for the electronic packaging industry [3-7]. Various SAC alloy systems have been proposed by Japanese (SAC305, short for Sn3.0Ag0.5Cu), EU (SAC387, short for Sn3.8Ag0.7Cu), and US (SAC396, short for Sn3.9Ag0.6Cu) consortiums [8], with the SAC305 alloy widely used by the industry as the most promising candidate for reliable $\mathrm{Pb}$-free solder due to its reliability under thermal cycling $[9,10]$.

Comparing conventional $\mathrm{Sn} 37 \mathrm{~Pb}$ eutectic solder $\left(183^{\circ} \mathrm{C}\right)$, the higher melting temperature of SAC305 $\left(217-221^{\circ} \mathrm{C}\right)$ limits its application when facing miniaturization challenges associated with emerging ultra-mobile computing, wearable devices, and the Internet of Things (IoT) markets [11]. Therefore, further studies have been carried out globally by industrial as well as academic consortiums on new $\mathrm{Pb}$-free alternatives [12-15]. Sn58Bi solder is gaining considerable attention because of its low melting temperature of $138^{\circ} \mathrm{C}[16,17]$, with other advantages of Sn-Bi-based solder associated with 
good solderability, superior mechanical properties, good joint strength, excellent creep resistance, low coefficient of thermal expansion $\left(\mathrm{CTE}, 1.5 \times 10^{-5} /{ }^{\circ} \mathrm{C}\right)$, and low cost [18].

A range of different nanoparticles have been added to Sn58Bi-based solder to investigate their effects. For example, $\mathrm{Al}_{2} \mathrm{O}_{3}$ nanoparticles were reported to strengthen the thermal properties, corrosion resistance, and creep performance [19]. Graphene nanosheets were found to refine the microstructure, enhance the wettability, corrosion resistance, tensile strength, ductility, hardness, and creep performance [20]. $\mathrm{SiC}$ nanoparticles were found to increase the shear strength of solder bumps on Si wafer, attributed to grain refinement and dispersion hardening [21]. In addition, nanostructured, cage-type polyhedral oligomeric silsesquioxane (POSS) were introduced to inhibit oxidation processes under high humidity and temperature, therefore mitigating $\mathrm{Sn}$ whisker growth in Sn58Bi, which is expected to benefit its reliability [22].

Microalloying, by addition of a trace amount of third element, is also believed to enhance the performance of Sn58Bi-based solder. Ni was found to refine the initial microstructure and enhance the tensile strength [23]. Zn was found to refine the microstructure as well as suppress the microstructure coarsening during aging, resulting in improved elongation and ultimate tensile strength (UTS) both before and after thermal aging [24]. Ti was also found to refine the microstructure and improve both UTS and yield strength (YS), even after aging [25]. Sb was reported to form SnSb IMCs that precipitated finely from the solid $\mathrm{Sn}$ solution near the grain boundaries with $\mathrm{Bi}$, and they suppressed the coarsening of the eutectic structure [26]. Rare earth (RE) elements such as Ce and La were found to greatly improve the wettability and shear strength of solder joints, as well as decrease the intermetallic layer (IML) thickening on $\mathrm{Cu}$ substrate [27]. Ag was reported to increase the alloy ductility, attributed to a substantial refinement of solidified microstructure [28]. More details regarding effects of microalloying on Sn-Bi solder can be found in a comprehensive review produced by the authors [13].

Sun et al. studied the effects of both Ag microalloy and Ag nanoparticles on Sn58Bi-based solder on electroless nickel immersion gold (ENIG) substrate, revealing that microalloyed Sn57.6Bi0.4Ag solder joints had better mechanical properties than nanoparticle-reinforced Sn58Bi + 0.4Ag solder joints after long-time aging, due to serious degeneration of Ag nanoparticle reinforcement [29]. Therefore, microalloyed Sn57.6Bi0.4Ag solder was selected in this study to conduct a joint scale reliability study.

The effect of microalloying Ag on Sn58Bi-based solder has been studied by different groups [26-30]. Although well studied, a board level joint scale reliability study of Ag microalloyed Sn58Bi solder joints produced with SMT has not been reported, and this is essential to assess its viability as an $\mathrm{SnPb}$ replacement. The combination of thermal fatigue and solder joint creep is considered to be a predominant failure mechanism of electronic assemblies, and it is of particular interest to end users requiring high reliability [31]. ATC is a widely used reliability evaluation technique that simultaneously produces static and strain-induced microstructural evolution in solders as a result of thermal expansion mismatch, thereby accelerating fatigue and creep damage mechanisms [10,12,32-37]. In this article, board level reliability of Sn58Bi-based solders is fully investigated using ATC. The influence of microalloying Ag on the mechanical performance and reliability of Sn58Bi is fully elucidated utilizing $\mathrm{Sn} 37 \mathrm{~Pb}$ as a control.

\section{Materials and Methods}

Alloys consisting of Sn58Bi and Sn57.6Bi0.4Ag were provided by Henkel (Hemel Hempstead, UK). The alloy was melted in a stainless steel crucible at $450{ }^{\circ} \mathrm{C}$, and then it was chill cast in a custom designed stainless steel mold at room temperature to form a thick dog-bone shaped ingot. The ingot was then sliced into tensile specimens of $2 \mathrm{~mm}$ thickness, as shown in Figure 1. The as-cast solder alloys were cross-sectioned, metallographically polished, and examined using a TM1000 scanning electron microscope (SEM, Hitachi, Tokyo, Japan) operated at an accelerating voltage of $1.5 \mathrm{kV}$ in backscattered electron (BSE) mode. 


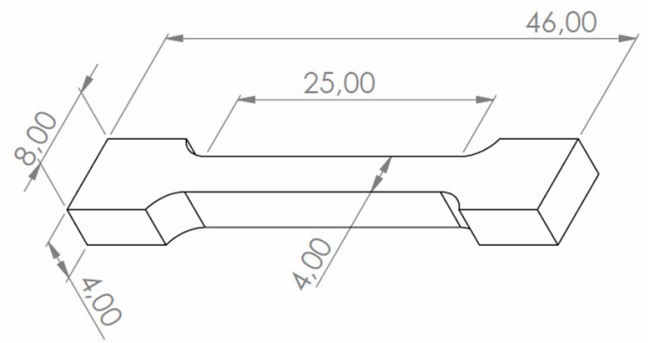

Figure 1. Schematic diagram of the specimen for tensile test (unit: $\mathrm{mm}$ ).

Tensile tests were performed at room temperature at a strain rate of $0.75 \mathrm{~mm} / \mathrm{min}\left(5 \times 10^{-4} \mathrm{~s}^{-1}\right)$ on an H25KS tensile tester(Tinius Olsen, Horsham, PA, USA). A ZHV30 Vickers hardness tester (ZwickRoell, Ulm, Germany) was used to determine the hardness of as-cast solder alloys. For each composition, five tests were carried out to achieve a statistical result. A phase identification of the various solder was carried out using an X'pert X-ray diffractometer (XRD, Phillips, Amsterdam, Netherlands) operated at $40 \mathrm{kV}$, and $\mathrm{Cu}-\mathrm{K} \alpha$ radiation was used at diffraction angles (2 $\theta)$ from $10^{\circ}$ to $90^{\circ}$ with a scanning speed of $1.2^{\circ} / \mathrm{min}$.

Solder pastes were produced utilizing a rosin-based flux. Commercial Sn37Pb solder paste was used in this study as a control. As shown in Figure 2, dummy components comprising 16 of 1206 chip resistors were soldered with these pastes on an FR4 printed circuit board (PCB) with a Cu organic solderability preservative (OSP) surface finish. The PCB was $1.55 \mathrm{~mm}$ thick and consisted of two layers. A standard right angle 37-pin D-type male connector was used to connect the PCB to an external data logger.

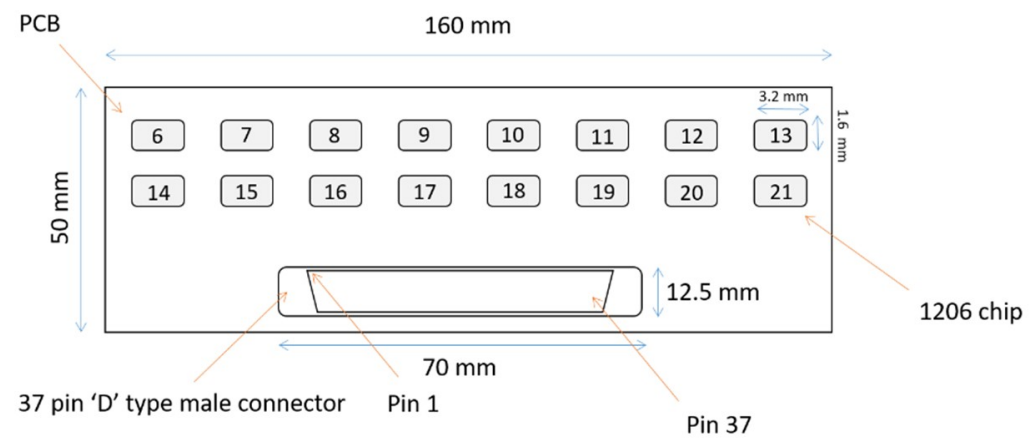

Figure 2. Printed circuit board (PCB) test board, including 16 of 1206 chip resistors and a type-D external connector.

A WT-180/40/5 environmental test chamber (Weiss Technik, Heuchelheim, Germany) was used to generate thermal cycling for all test vehicles. A $0-100^{\circ} \mathrm{C}$ cycle was imposed, which had a ramp rate of $6.7^{\circ} \mathrm{C} / \mathrm{min}$ on heating and $4{ }^{\circ} \mathrm{C} / \mathrm{min}$ on cooling. The dwell times were $10 \mathrm{~min}$ at both the high and low extremes of the cycle. During ATC, the solder joints were monitored continuously with a 128/256 STD event detector (Analysis Tech, Wakefield, MA, USA) set at a resistance limit of $1000 \Omega$. Data were recorded and stored using the WinDatalog software (V3.4.0, Analysis Tech, Wakefield, MA, USA). In accordance with the IPC-9701A industry test guideline, a spike of $1000 \Omega$ for $0.2 \mathrm{~ms}$ followed by nine additional events within $10 \%$ of the cycles to the initial event was marked as a failure [38].

\section{Results}

\subsection{Microstructure}

The microstructure of as-solidified Sn58Bi and Sn57.6B i0.4Ag solder alloys are shown in Figures 3 and 4. The microstructure of Sn58Bi alloy is made up of two phases, Sn phase (black area) and Bi 
phase (white area). This has been identified in XRD patterns shown in Figure 5. As the content of Ag microalloy was low $(0.4 \mathrm{wt} . \%)$, the XRD patterns of the two solder alloys were similar.

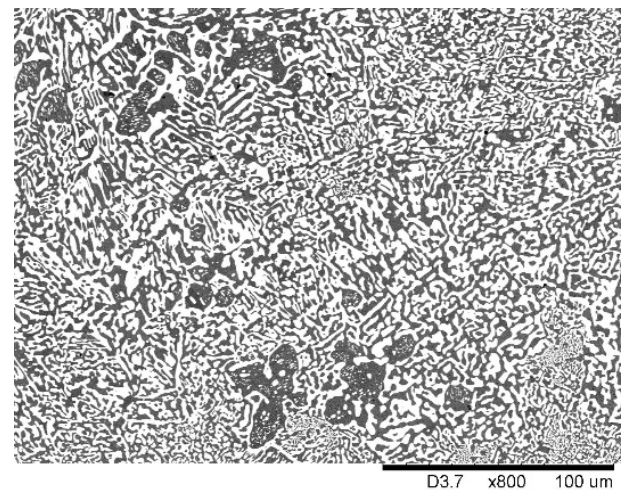

(a)

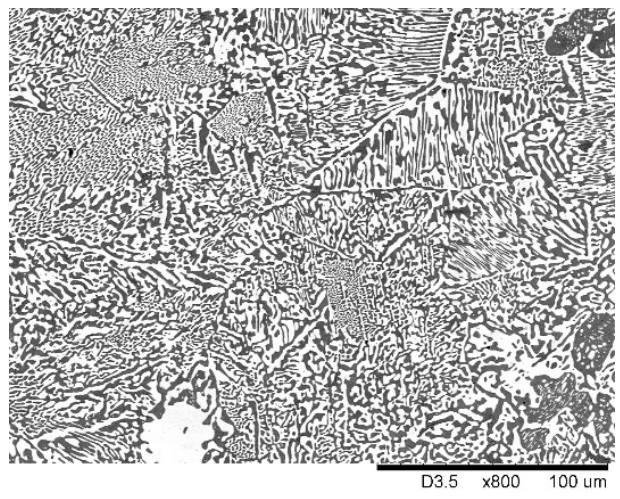

(b)

Figure 3. Microstructure at lower magnification (×800): (a) Sn58Bi and (b) Sn57.6Bi0.4Ag.

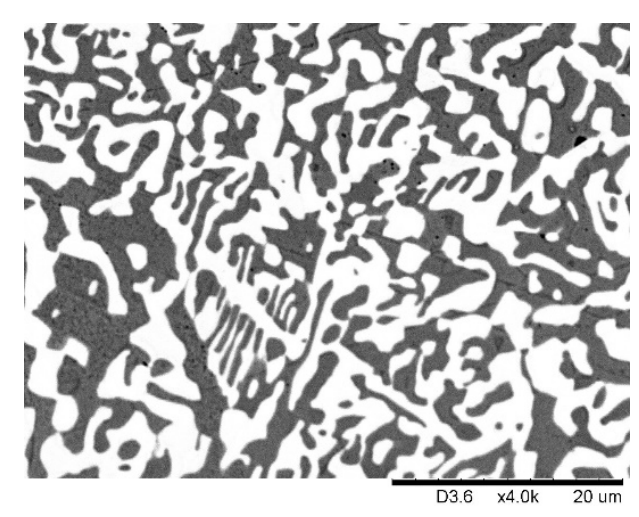

(a)

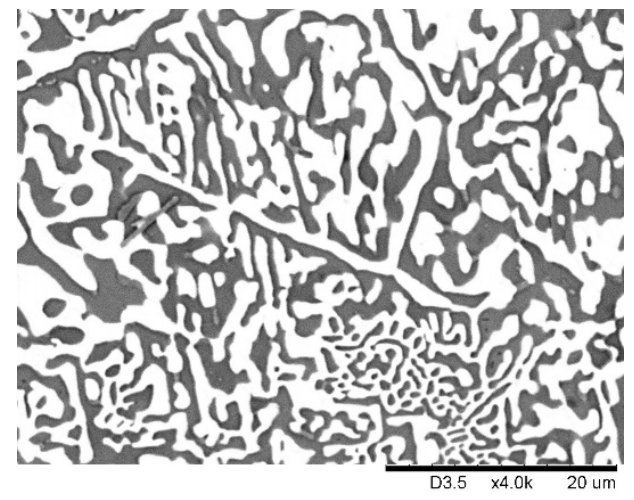

(b)

Figure 4. Microstructure at higher magnification $(\times 4000)$ : (a) Sn58Bi and (b) Sn57.6Bi0.4Ag.

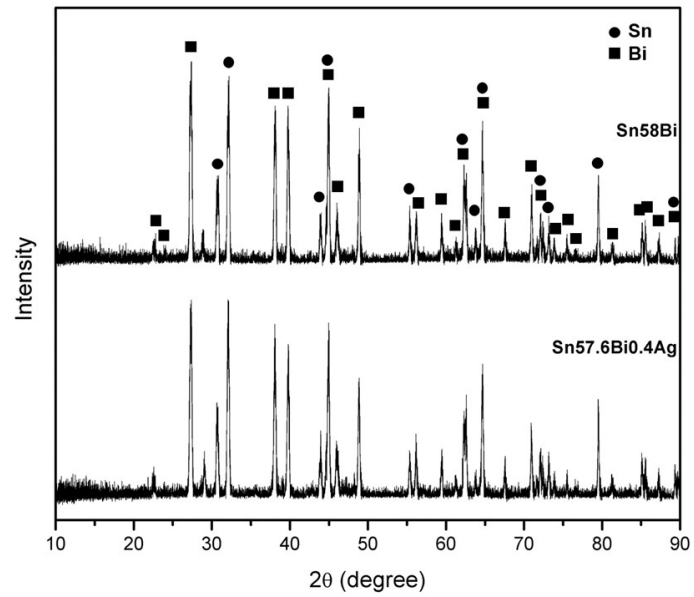

Figure 5. X-ray diffraction (XRD) patterns of Sn58Bi and Sn57.6Bi0.4Ag.

Sn57.6Bi0.4Ag showed slightly more refined microstructure than $\mathrm{Sn} 58 \mathrm{Bi}$, and this was attributed to microalloying of $\mathrm{Ag}$. In the microstructure of $\mathrm{Sn} 57.6 \mathrm{Bi} 0.4 \mathrm{Ag}$, an extra rod-like phase could be observed, as shown in Figure 6. According to the phase diagram of $\mathrm{Sn}-\mathrm{Bi}-\mathrm{Ag}$, as shown in Figure 7, 
this phase was confirmed to be $\mathrm{Ag}_{3} \mathrm{Sn}$ IMCs precipitated from the $\mathrm{Sn}$ matrix. However, an $\mathrm{Ag}_{3} \mathrm{Sn}$ phase was not detected in XRD, presumably due to its limited content.



(a)

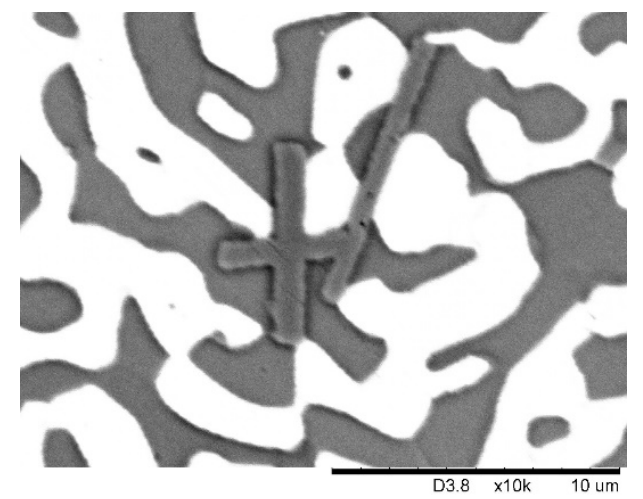

(b)

Figure 6. Rod-like phase discovered in Sn57.6Bi0.4Ag solder alloy: (a) $\times 4000$ magnification and (b) $\times 10,000$ magnification.

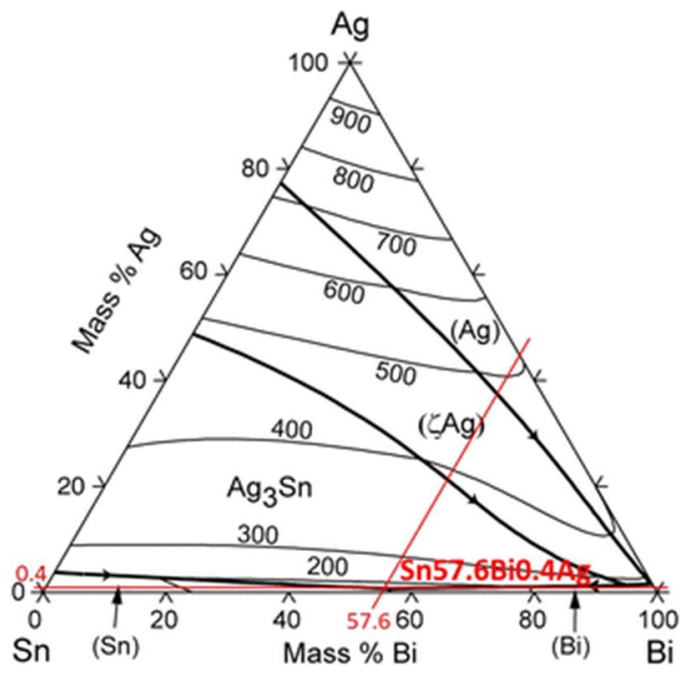

Figure 7. The phase diagram of $\mathrm{Sn}-\mathrm{Bi}-\mathrm{Ag}$ alloy, reproduced from [29], with permission from Springer Nature, 2014.

\subsection{Mechanics}

Figure 8 shows the typical tensile stress-strain curves of Sn58Bi-based solder alloys. UTS, YS (represented by $0.2 \%$ proof stress), elongation, Young's modulus, and microhardness of each alloy are listed in Table 1 as well as presented in Figure 9. It can be clearly observed that UTS, YS, and Young's modulus of Sn58Bi-based solder alloy were all slightly increased by microalloying $0.4 \mathrm{wt} . \%$ Ag. UTS of Sn57.6Bi0.4Ag alloy was $58.7 \mathrm{MPa}$, which was $6.7 \%$ higher than that of Sn37Pb eutectic alloy (55 MPa) [39] and 2.6\% higher than that of Sn58Bi (57.2 MPa). It is worth noting that the YS of Sn58Bi solder alloy was improved by $1.8 \%$, to $46 \mathrm{MPa}$, with the addition of $0.4 \mathrm{wt} . \%$ Ag. Also, the Young's modulus was raised by $14.7 \%$ as compared with Sn58Bi. While the tensile strength increased, the Ag microalloy had a negligible effect on the microhardness of Sn58Bi. The elongation, however, was decreased by $10.6 \%$ with Ag addition, compared with that of original Sn58Bi. 


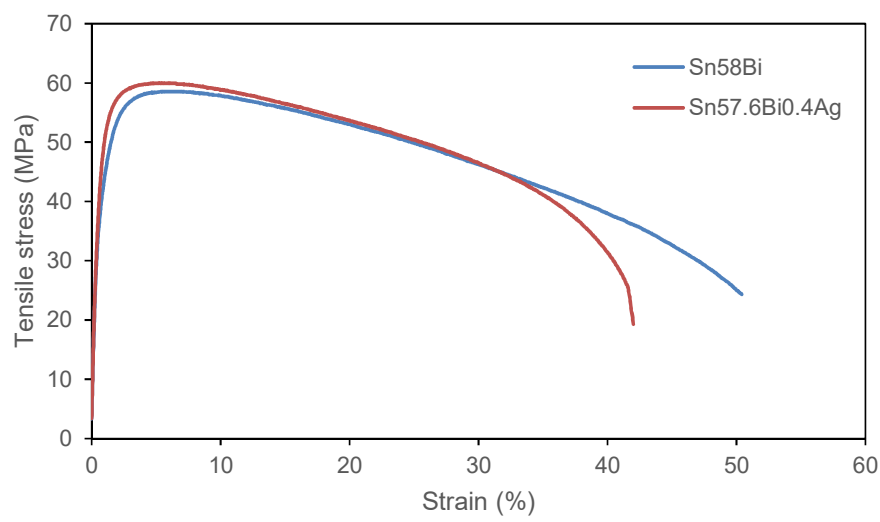

Figure 8. Tensile curves of Sn58Bi and Sn57.6Bi0.4Ag.

Table 1. Mechanical property results.

\begin{tabular}{cccccc}
\hline Alloy & UTS (MPa) & YS (MPa) & Elongation (\%) & Young's Modulus (GPa) & Microhardness (HV) \\
\hline Sn58Bi & 57.2 & 45.2 & 54.6 & 5.0 & 19.9 \\
\hline Sn57.6Bi0.4Ag & 58.7 & 46.0 & 48.9 & 5.7 & 19.8 \\
\hline
\end{tabular}

(a)

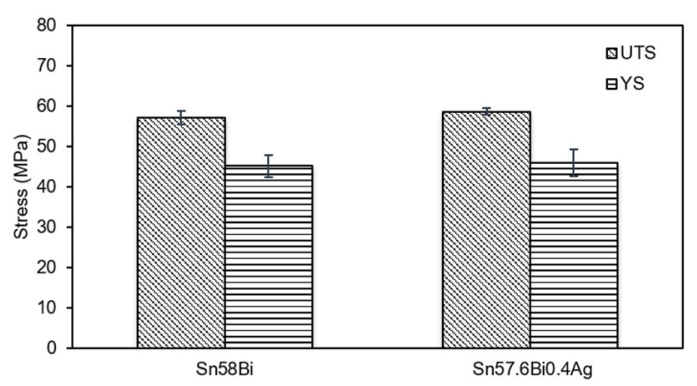

(c)

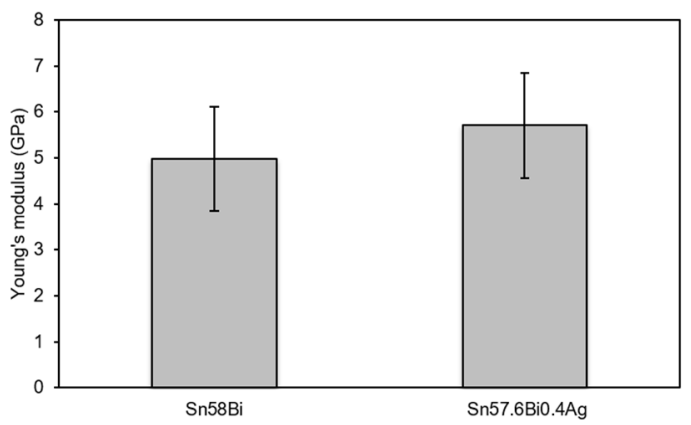

(b)



(d)



Figure 9. The comparison of mechanical properties: (a) UTS and YS, (b) elongation, (c) Young's modulus, and (d) microhardness, for Sn58Bi and Sn57.6Bi0.4Ag solder alloys.

\subsection{Reliability}

Reliability data was fit to a two-parameter Weibull distribution:

$$
F(t)=1-\exp \left[-(t / \eta)^{\beta}\right]
$$

where $F(t)$ is the unreliability rate, $t$ is the time (number of cycles), $\eta$ is the scale parameter (or characteristic life), and $\beta$ is the shape parameter (or slope). 
The two-parameter Weibull distribution is shown in Figure 10. A summary of test results is given in Table 2. N63.2, the number of cycles to $63.2 \%$ failures [4], was used to express the characteristic life in this study.

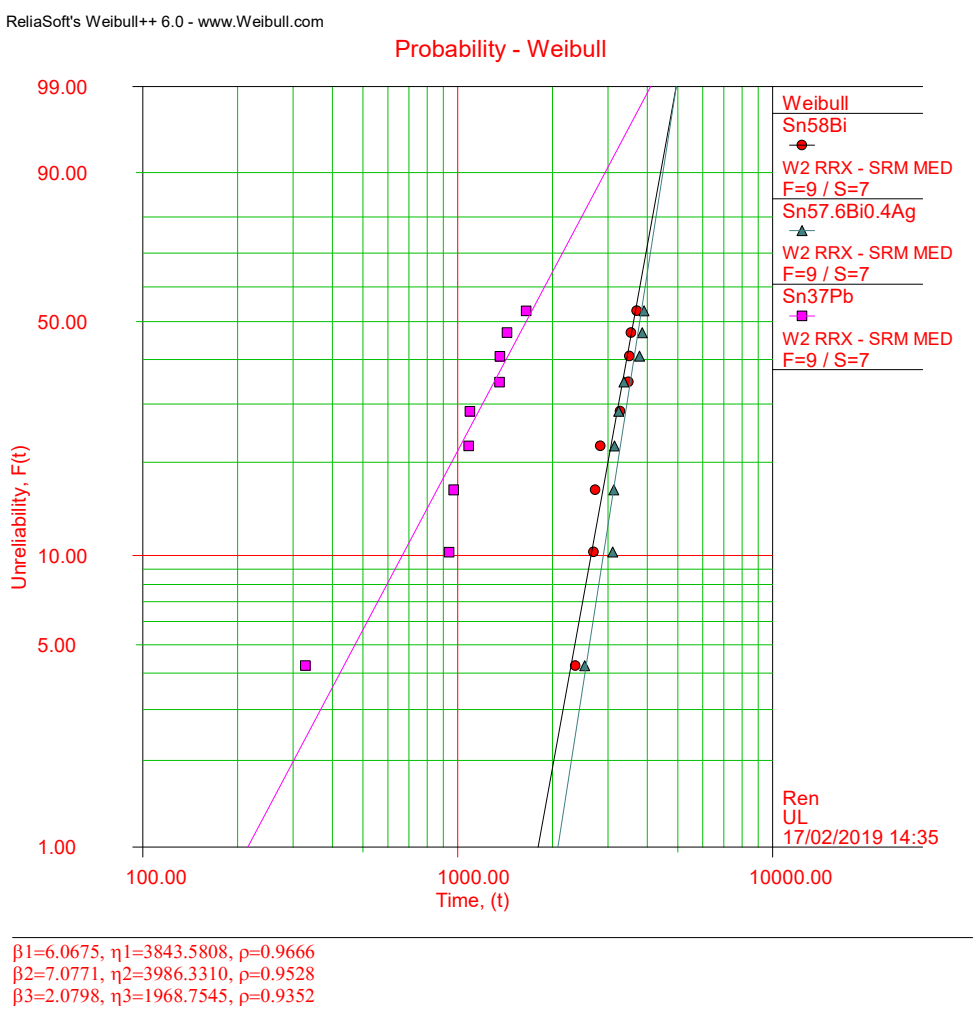

Figure 10. Weibull logarithm plot of solder joint lifetime for 1206 chip resistors.

Table 2. Result of the board level solder joint reliability test.

\begin{tabular}{ccc}
\hline Solder & Characteristic Lifetime, $\boldsymbol{\eta}$ & Shape Parameter, $\boldsymbol{\beta}$ \\
\hline Sn37Pb & 1969 & 2.08 \\
Sn58Bi & 3844 & 6.07 \\
Sn57.6Bi0.4Ag & 3986 & 7.08 \\
\hline
\end{tabular}

Both Sn58Bi and Sn57.6Bi0.4Ag solders showed an approximately doubled characteristic lifetime compared with conventional Sn37Pb solder. Upon microalloying Ag, lifetime of Sn58Bi was marginally increased. Their lifetimes were ranked as follows: Sn57.6Bi0.4Ag $>$ Sn58Bi $>>$ Sn37Pb. Compared with Sn37Pb, Sn58Bi and Sn57.6Bi0.4Ag showed much higher shape parameters, indicating solder joints failed within a relatively short time span.

\section{Discussion}

The phenomenon of microstructure refinement is commonly observed in microalloyed, low-temperature solder alloys [23-29,40]. By microalloying Ag, the microstructure of Sn58Bi alloy becomes more refined whilst $\mathrm{Ag}_{3} \mathrm{Sn}$ intermetallic compounds form. These intermetallics enhance strength through a precipitation hardening mechanism, which in turn deteriorates ductility due to their inherent brittleness.

The simultaneous combination of these two mechanisms, microstructure refinement and precipitation hardening, improves the mechanical properties of Sn57.6Bi0.4Ag, and this manifests itself in an enhanced reliability performance. The improved reliability may also result from an initial finer microstructure, which coarsened at a slower rate under the stresses imposed by the thermal cycling. 
The $\mathrm{Ag}_{3} \mathrm{Sn}$ intermetallic particle as a result of microalloying seems to have a dispersion-strengthening effect that enhances the solder joints too. Similar effects of Ag microalloying on solder reliability have been reported by Collins et al. [10]. In addition, it is postulated that during thermal cycling, $\mathrm{Ag}_{3} \mathrm{Sn}$ intermetallic compounds are located at the $\mathrm{Sn}-\mathrm{Bi}$ phase boundaries, and they suppress the solder microstructure from coarsening through a grain boundary pinning effect, therefore extending the time to failure for these alloys.

\section{Conclusions}

It is concluded from this study that by adding small amount of $\mathrm{Ag}(0.4 \mathrm{wt} . \%)$ into Sn58Bi solder alloy:

1. Mechanical properties, including tensile strength, yield strength, and Young's modulus are improved as a result of the combination of microstructural refinement and precipitation hardening.

2. Ductility is deteriorated as a result of the formation of brittle $\mathrm{Ag}_{3} \mathrm{Sn}$ IMCs.

3. Board level reliability of solder joints is enhanced during ATC testing. $\mathrm{Ag}_{3} \mathrm{Sn}$ IMCs are assumed to be located at the $\mathrm{Sn}-\mathrm{Bi}$ phase boundaries, and this leads to a suppression of coarsening in the solder microstructure.

Author Contributions: Conceptualization, G.R. and M.N.C.; methodology, G.R.; validation, G.R. and M.N.C.; formal analysis, G.R.; investigation, G.R.; resources, G.R.; data curation, G.R.; writing-original draft preparation, G.R.; writing-review and editing, G.R. and M.N.C.; visualization, G.R.; supervision, M.N.C.; project administration, M.N.C.; funding acquisition, G.R. and M.N.C.

Funding: This work has been funded by the Irish Research Council in partnership with Henkel Ltd. under the Enterprise Partnership Scheme grant number EPSG/2014/48.

Conflicts of Interest: The authors declare no conflict of interest. The funders had no role in the design of the study; in the collection, analyses, or interpretation of data; in the writing of the manuscript, or in the decision to publish the results.

\section{References}

1. Compliance FAQs: RoHS. Available online: https://www.nist.gov/standardsgov/compliance-faqs-rohs (accessed on 21 January 2019).

2. Kotadia, H.R.; Howes, P.D.; Mannan, S.H. A review: On the development of low melting temperature Pb-free solders. Microelectron. Reliab. 2014, 54, 1253-1273. [CrossRef]

3. Henshall, G.; Healey, R.; Pandher, R.S.; Sweatman, K.; Howell, K.; Coyle, R.; Sack, T.; Snugovsky, P.; Tisdale, S.; Hua, F. iNEMI Pb-free alloy alternatives project report: State of the industry. In Proceedings of the SMTA International Conference and Exhibition, Orlando, FL, USA, 17-22 August 2008.

4. Shangguan, D. Lead-Free Solder Interconnect Reliability; ASM International: Geauga County, OH, USA, 2005.

5. Ma, H.; Suhling, J.C. A review of mechanical properties of lead-free solders for electronic packaging. J. Mater. Sci. 2009, 44, 1141-1158. [CrossRef]

6. Bradley, E.; Handwerker, C.A.; Bath, J.; Parker, R.D.; Gedney, R.W. Lead-Free Electronics: iNEMI Projects Lead to Successful Manufacturing; John Wiley \& Sons: Hoboken, NJ, USA, 2007.

7. Suganuma, K. Advances in lead-free electronics soldering. Curr. Opin. Solid State Mater. Sci. 2001, 5, 55-64. [CrossRef]

8. Tang, Y.; Li, G.Y.; Pan, Y.C. Influence of $\mathrm{TiO}_{2}$ nanoparticles on IMC growth in $\mathrm{Sn}-3.0 \mathrm{Ag}-0.5 \mathrm{Cu}-x \mathrm{TiO}_{2}$ solder joints in reflow process. J. Alloys Compd. 2013, 554, 195-203. [CrossRef]

9. Collins, M.N.; Punch, J.; Coyle, R. Surface finish effect on reliability of SAC 305 soldered chip resistors. Soldering Surf. Mount Technol. 2012, 24, 240-248. [CrossRef]

10. Collins, M.N.; Punch, J.; Coyle, R.; Reid, M.; Popowich, R.; Read, P.; Fleming, D. Thermal fatigue and failure analysis of $\mathrm{SnAgCu}$ solder alloys with minor Pb additions. IEEE Trans. Compon. Packag. Manuf. Technol. 2011, 1, 1594-1600. [CrossRef] 
11. Fu, H.; Aspandiar, R.; Chen, J.; Cheng, S.; Chen, Q.; Coyle, R.; Feng, S.; Hardin, B.; Krmpotich, M.; Mokler, S.; et al. iNEMI Project on Process Development of Bisn-Based Low Temperature Solder Pastes-Part II: Characterization of Mixed Alloy BGA Solder Joints. In Proceedings of the 2018 Pan Pacific Microelectronics Symposium (Pan Pacific), Waimea, HI, USA, 5-8 February 2018.

12. Jackson, G.J.; Wilding, I.J.; Boyle, R.; Collins, M.N.; Dalton, E.; Punch, J.; Liu, P.; Holloway, M. SnZn Solder Alternative For Low-Cost Pb-Free Surface Mount Assemblies. In Proceedings of the SMTA International Conference and Exhibition, Orlando, FL, USA, 14-18 February 2012.

13. Ren, G.; Wilding, I.J.; Collins, M.N. Alloying influences on low melt temperature SnZn and SnBi solder alloys for electronic interconnections. J. Alloys Compd. 2016, 665, 251-260. [CrossRef]

14. Collins, M.N.; Jackson, G.J.; Dalton, E.; Steen, H.; Liu, P.; Holloway, M.; Punch, J. Accelerated Temperature Cycling and Microstructural Analysis of SnZn Solder in Surface Mount Assemblies. In Proceedings of the ICSR (Soldering and Reliability), Toronto, ON, Canada, 15-18 May 2012.

15. Ren, G.; Collins, M.N. On the mechanism of Sn tunnelling induced intermetallic formation between Sn-8Zn-3Bi solder alloys and Cu substrates. J. Alloys Compd. 2019, 791, 559-566. [CrossRef]

16. Lee, H.; Choi, K.-S.; Eom, Y.-S.; Bae, H.-C.; Lee, J.H. Sn58Bi Solder Interconnection for Low-Temperature Flex-on-Flex Bonding. ETRI J. 2016, 38, 1163-1171. [CrossRef]

17. Zhang, S.; Paik, K.-W. A Study on the Failure Mechanism and Enhanced Reliability of Sn58Bi Solder Anisotropic Conductive Film Joints in a Pressure Cooker Test Due to Polymer Viscoelastic Properties and Hydroswelling. IEEE Trans. Compon. Packag. Manuf. Technol. 2016, 6, 216-223. [CrossRef]

18. Goh, Y.; Haseeb, A.S.M.A.; Sabri, M.F.M. Effects of hydroquinone and gelatin on the electrodeposition of $\mathrm{Sn}$-Bi low temperature Pb-free solder. Electrochim. Acta 2013, 90, 265-273. [CrossRef]

19. Zhu, W.B.; Ma, Y.; Li, X.Z.; Zhou, W.; Wu, P. Effects of $\mathrm{Al}_{2} \mathrm{O}_{3}$ nanoparticles on the microstructure and properties of Sn58Bi solder alloys. J. Mater. Sci. Mater. Electron. 2018, 29, 7575-7585. [CrossRef]

20. Ma, Y.; Li, X.Z.; Zhou, W.; Yang, L.Z.; Wu, P. Reinforcement of graphene nanosheets on the microstructure and properties of Sn58Bi lead-free solder. Mater. Des. 2017, 113, 264-272. [CrossRef]

21. Shin, Y.S.; Ko, Y.K.; Kim, J.K.; Yoo, S.; Lee, C.W. SiC-NANOPARTICLE DISPERSED COMPOSITE SOLDER BUMPS FABRICATED BY ELECTROPLATING. Surf. Rev. Lett. 2010, 17, 201-205. [CrossRef]

22. Zuo, Y.; Ma, L.M.; Liu, S.H.; Shu, Y.T.; Guo, F. WHISKER MITIGATION FOR Sn-BASED Pb-FREE SOLDERS BY POSS ADDITION. Acta Metall. Sinica 2015, 51, 685-692.

23. Kanlayasiri, K.; Ariga, T. Physical properties of Sn58Bi-xNi lead-free solder and its interfacial reaction with copper substrate. Mater. Des. 2015, 86, 371-378. [CrossRef]

24. Zhou, S.Q.; Mokhtari, O.; Rafique, M.G.; Shunmugasamy, V.C.; Mansoor, B.; Nishikawa, H. Improvement in the mechanical properties of eutectic Sn58Bi alloy by 0.5 and $1 \mathrm{wt} \% \mathrm{Zn}$ addition before and after thermal aging. J. Alloys Compd. 2018, 765, 1243-1252. [CrossRef]

25. Zhou, S.Q.; Liu, X.D.; Mokhtari, O.; Nishikawa, H. The evaluation of mechanical properties of Sn58BiXTi solder by tensile test. In Proceedings of the 2017 18th International Conference on Electronic Packaging Technology (ICEPT), Harbin, China, 16-19 August 2017; pp. 703-707.

26. Sakuyama, S.; Akamatsu, T.; Uenishi, K.; Sato, T. Effects of a third element on microstructure and mechanical properties of eutectic Sn-Bi solder. Trans. Jpn. Inst. Electron. Packag. 2009, 2, 98-103. [CrossRef]

27. Dong, W.; Shi, Y.; Xia, Z.; Lei, Y.; Guo, F. Effects of trace amounts of rare earth additions on microstructure and properties of Sn-Bi-based solder alloy. J. Electron. Mater. 2008, 37, 982-991. [CrossRef]

28. McCormack, M.; Chen, H.S.; Kammlott, G.W.; Jin, S. Significantly improved mechanical properties of Bi-Sn solder alloys by Ag-doping. J. Electron. Mater. 1997, 26, 954-958. [CrossRef]

29. Sun, H.Y.; Li, Q.Q.; Chan, Y.C. A study of Ag additive methods by comparing mechanical properties between Sn57.6Bi0.4Ag and 0.4 wt\% nano-Ag-doped Sn58Bi BGA solder joints. J. Mater. Sci. Mater. Electron. 2014, 25, 4380-4390. [CrossRef]

30. Suganuma, K.; Sakai, T.; Kim, K.S.; Takagi, Y.; Sugimoto, J.; Ueshima, M. Thermal and mechanical stability of soldering QFP with Sn-Bi-Ag lead-free alloy. IEEE Trans. Electron. Packag. Manuf. 2002, 25, $257-261$. [CrossRef]

31. Engelmaier, W. Surface mount solder joint long-term reliability: Design, testing, prediction. Soldering Surf. Mount Technol. 1989, 1, 14-22. [CrossRef] 
32. Coyle, R.; Osenbach, J.; Collins, M.N.; McCormick, H.; Read, P.; Fleming, D.; Popowich, R.; Punch, J.; Reid, M.; Kummerl, S.; et al. Phenomenological Study of the Effect of Microstructural Evolution on the Thermal Fatigue Resistance of Pb-Free Solder Joints. IEEE Trans. Compon. Packag. Manuf. Technol. 2011, 1, 1583-1593. [CrossRef]

33. Xu, H.; Lee, T.-K.; Kim, C.-U. Fatigue properties of lead-free solder joints in electronic packaging assembly investigated by isothermal cyclic shear fatigue. In Proceedings of the 2014 IEEE 64th Electronic Components and Technology Conference (ECTC), Orlando, FL, USA, 27-30 May 2014; pp. 133-138.

34. Dalton, E.; Ren, G.; Punch, J.; Collins, M.N. Accelerated temperature cycling induced strain and failure behaviour for BGA assemblies of third generation high Ag content Pb-free solder alloys. Mater. Des. 2018, 154, 184-191. [CrossRef]

35. Collins, M.N.; Dalton, E.; Punch, J. Microstructural influences on thermomechanical fatigue behaviour of third generation high Ag content Pb-Free solder alloys. J. Alloys Compd. 2016, 688, 164-170. [CrossRef]

36. Coyle, R.; Reid, M.; Ryan, C.; Popowich, R.; Read, P.; Fleming, D.; Collins, M.; Punch, J.; Chatterji, I. The Influence of the $\mathrm{Pb}$-free Solder Alloy Composition and Processing Parameters on Thermal Fatigue Performance of a Ceramic Chip Resistor. In Proceedings of the 2009 59th Electronic Components and Technology Conference, San Diego, CA, USA, 26-29 May 2009; pp. 423-430.

37. Coyle, R.; Osenbach, J.; Read, P.; McCormick, H.; Fleming, D.; Popowich, R.; Reid, M.; Punch, J.; Collins, M.N.; Kinyanjui, R.; et al. Dwell Time, Microstructural Dependencies, and the Interpretation of Thermal Fatigue Test Data of $\mathrm{SnPb}$ and $\mathrm{Pb}$-free Solders. In Proceedings of the SMTA International Conference and Exhibition, San Diego, CA, USA, 4-8 October 2009.

38. Ghaffarian, R. CCGA packages for space applications. Microelectron. Reliab. 2006, 46, 2006-2024. [CrossRef]

39. Liu, S.; Xue, S.; Xue, P.; Luo, D. Present status of Sn-Zn lead-free solders bearing alloying elements. J. Mater. Sci. Mater. Electron. 2015, 26, 4389-4411. [CrossRef]

40. Ren, G.; Collins, M.N. The effects of antimony additions on microstructures, thermal and mechanical properties of Sn-8Zn-3Bi alloys. Mater. Des. 2017, 119, 133-140. [CrossRef]

(C) 2019 by the authors. Licensee MDPI, Basel, Switzerland. This article is an open access article distributed under the terms and conditions of the Creative Commons Attribution (CC BY) license (http://creativecommons.org/licenses/by/4.0/). 